\title{
Differential Root Proteome Expression in Tomato Genotypes with Contrasting Drought Tolerance Exposed to Dehydration
}

\author{
Suping Zhou', Marsha Palmer, Jing Zhou, and Sarabjit Bhatti \\ Department of Agricultural Sciences, College of Agriculture, Human and Natural Sciences, Tennessee \\ State University, 3500 John A. Merritt Boulevard, Nashville, TN 37209
}

Kevin J. Howe, Tara Fish, and Theodore W. Thannhauser ${ }^{1}$
Plant, Soil and Nutrition Research Unit, USDA-ARS, Tower Rd, Ithaca, NY 14853

AdDitional INDEX words. Solanum chilense, cultivar, iTRAQ, post-transcriptional regulation, protein translation, signal transduction, cellular metabolic pathways, stress proteins, protein folding, proteases, cell cycle

\begin{abstract}
A comparative proteomics study using isobaric tags for relative and absolute quantitation (iTRAQ) was performed on a mesophytic tomato (Solanum lycopersicum) cultivar and a dehydration-resistant wild species (Solanum chilense) to identify proteins that play key roles in tolerance to water deficit stress. In tomato 'Walter' LA3465, 130 proteins were identified, of which $104(80 \%)$ were repressed and $26(20 \%)$ were induced. In S. chilense LA1958, a total of 170 proteins were identified with $106(62 \%)$ repressed and $64(38 \%)$ induced. According to their putative molecular functions, the differentially expressed proteins belong to the following subgroups: stress proteins, gene expression, nascent protein processing, protein folding, protein degradation, carbohydrate metabolism, amino acid and nucleotide metabolism, lipid metabolism, signal transduction, and cell cycle regulation. Based on changes in protein abundance induced by the dehydration treatment, cellular metabolic activities and protein biosynthesis were suppressed by the stress. In $\boldsymbol{S}$. chilense, dehydration treatment led to elevated accumulation of proteins involved in post-transcriptional gene regulation and fidelity in protein translation including prefoldin, which promotes protein folding without the use of adenosine-5' -triphosphate (ATP), several hydrophilic proteins, and calmodulin in the calcium signal transduction pathway. Those protein changes were not found in the susceptible tomato, 'Walter'. Within each functional protein group, proteins showing opposite changes (dehydration induced vs. repressed) in the two species were identified and roles of those proteins in conferring tolerance to water deficit stress are discussed. Information provided in this report will be useful for selection of proteins or genes in analyzing or improving dehydration tolerance in tomato cultivars.
\end{abstract}

Adequate hydration is essential for normal plant growth and development. Water deficit induces physiological stresses, resulting in disturbance of membrane structural stability and a burst in production of reactive oxygen species (Bartels and Erik, 2004; De Carvalho, 2008). Metabolic reactions are redirected to produce stress-protectant substances such as compatible solutes and antioxidants and for the removal of toxic compounds and denatured or damaged DNA and protein molecules (Fulda et al., 2011; Hajheidari et al., 2007; Shinozaki and Yamaguchi-Shinozaki, 2007). Plants have developed various strategies to survive both short- and long-term water deficit conditions by using various avoidance and/or tolerance strategies (Harb et al., 2010; Price et al., 2002), which include shortened phenological cycles (Degenkolbe et al., 2009) and altered plant architectural structures (smaller plants, smaller

Received for publication 11 June 2012. Accepted for publication 3 Dec. 2012. This project was supported by the Agriculture and Food Research Initiative competitive grant no. 2010-65114-20405 from the USDA National Institute of Food, and Agriculture, NIFA-1890 Capacity Building Program, and EvansAllen Research Funds.

Mention of trade names or commercial products in this publication is solely for the purpose of providing specific information and does not imply recommendation or endorsement by the U.S. Department of Agriculture.

We thank Drs. Roger Sauve and Dafeng Hui and Mr. Timothy Cooper at Tennessee State University for their critical review of the manuscript.

${ }^{1}$ To whom inquiries over iTRAQ should be addressed. E-mail: Ted. Thannhauser@ars.usda.gov.

${ }^{2}$ Corresponding author. E-mail: zsuping@tnstate.edu. and thicker leaves, larger and deeper root systems, etc.) (Bengough et al., 2011; Zhang et al., 2009).

Proteins are the primary functional biomolecules for the expression of genomic information in cells. The stress proteome refers to all the proteins that contribute to realizing the cellular stress response (Kültz, 2003). Alteration of proteome expression in response to water deficit involves a large number of proteins with as many as 500 proteins in the rice roots [Oryza sativa (Mirzaei et al., 2012)] and over 100 proteins in wheat [Triticum aestivum (Ford et al., 2011)] affected by the stress. These proteins are responsible for various functions thus affecting multiple cellular functional pathways. As a result of such systematic and multifaceted changes from gene expression to physiological and biochemical reactions in response to the dehydration (water deficit) stress, it remains very challenging to determine the master elements for the tolerance mechanism.

Tomato cultivars are mesophyte plants, generally requiring a more or less continuous water supply. A wild tomato species, Solanum chilense, which is indigenous to arid and rocky areas in South America, has been found to be highly tolerant to extreme water deficit (Chetelat et al., 2009; Rick, 1973; Xia et al., 2010). In this study, the dehydration stress proteomes in the tolerant species ( $S$. chilense) and a susceptible tomato cultivar (Walter) were identified using iTRAQ proteomics analysis. Molecular mechanisms for tolerance to the water deficit stress factor were developed based on differential protein expression between the two tomato species and in reference 
of the function of the respective protein (or gene) reported from previous investigations. This study has identified proteins that were affected differentially in the two species; those proteins are more directly linked to the molecular mechanisms that plants would use to develop tolerance to dehydration stress. Information provided in this report will be very useful in selecting genes for studying or breeding for tolerance to water deficit conditions in tomato.

\section{Materials and Methods}

Plant dehydration treatment. Seed stocks of $S$. chilense LA1958 and tomato 'Walter' LA3465 were obtained from The C.M. Rick Tomato Genetics Resource Center, University of California, Davis. Germinated seeds were grown to the two-leaf stage in seedling cubes (Smithers-Oasis, Kent, $\mathrm{OH}$ ) and then transferred into net pots $(3.81 \mathrm{~cm}$ wide) filled with hydroteon clay balls (Hydrofarm, Seattle, WA) and continued to grow in half-strength Hoagland's nutrient solution (Hoagland and Arnon, 1950) to the four-leaf stage (Zhou et al., 2011). The greenhouse conditions were set at $25{ }^{\circ} \mathrm{C}$ from 0500 to $2000 \mathrm{HR}$ and $21{ }^{\circ} \mathrm{C}$ during the remaining dark period with no supplemental lighting.

Plant dehydration treatments and iTRAQ analysis were performed following the workflow described in Figure 1. Dehydration treatment was applied by removing plants from the hydroponic solution. The treatment started in late afternoon when no direct sunlight reached the greenhouse (1900 HR in April at Nashville, TN) to minimize water loss through stomatal evaporation. The treatment lasted through the night and was ended the next morning at the first sign of leaf droop (wilt), which occurred within $30 \mathrm{~min}$ after strong sunlight reached the greenhouse ( 0830 to $0900 \mathrm{HR}$ ). The control plants remained in the hydroponic solution during the treatment period and they were harvested at the same time point. Three biological replicates (in three tanks each growing 20 plants) were conducted for both the control and treated samples. To collect tissues for protein analysis, the root was cut $1 \mathrm{~cm}$ below the bottom of the net pots, and the tissue below the cut was collected and immediately frozen in liquid nitrogen.

Protein EXTRACTION AND ISOBARIC TAGS FOR RELATIVE AND ABSOLUTE QUANTITATION LABELING. Tissues were ground into a fine powder under liquid nitrogen and then re-suspended in acetone supplemented with $10 \%$ trichloroacetic acid and $1 \%$ dithiothreitol (Sigma, St. Louis, MO). After incubation at $-20{ }^{\circ} \mathrm{C}$ overnight followed by centrifugation at $12,000 g_{\mathrm{n}}$ for 10 min at $4{ }^{\circ} \mathrm{C}$, protein pellets were collected and washed four times with pre-chilled acetone and finally evaporated to nearcomplete dryness (Zhou et al., 2009, 2011). After adding a dissolution buffer $(1: 10, \mathrm{w} / \mathrm{v})$ consisting of $50 \mathrm{~mm}$ triethylammonium bicarbonate (TEAB) and $500 \mathrm{~mm}$ urea (Sigma), protein powder was incubated on ice for $10 \mathrm{~min}$ followed by centrifugation at $10,000 g_{\mathrm{n}}$ for $10 \mathrm{~min}$. Proteins in the supernatant were precipitated using the methanol and chloroform method (Wessel and Fugge, 1984). Proteins were dissolved in the same dissolution buffer, and protein content was determined using a protein assay kit (Bio-Rad, Hercules, CA). All protein samples were adjusted to the same concentration with respect to protein $\left(2 \mu \mathrm{g} \cdot \mu \mathrm{L}^{-1}\right)$, urea $(1 \mathrm{M})$, and TEAB $(100 \mathrm{~mm})$ by diluting with $6 \mathrm{M}$ urea and $1 \mathrm{M}$ TEAB buffer.

For iTRAQ labeling, $50 \mu \mathrm{L}$ containing $100 \mu \mathrm{g}$ protein from each sample was reduced to $25 \mu \mathrm{L}$ under vacuum. Peptides

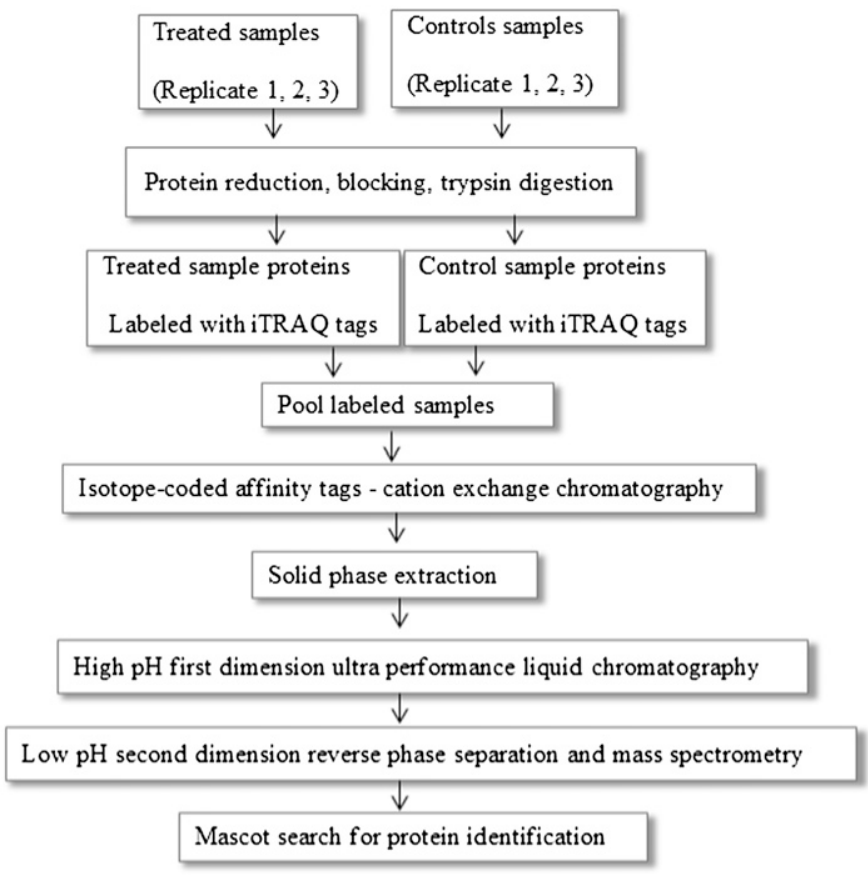

Fig. 1. Workflow of isobaric tags for relative and absolute quantitation (iTRAQ) analysis of dehydration-treated root proteomes in Solanum lycopersicum 'Walter' and Solanum chilense. Tomato seedlings were exposed to dehydration treatments. Three biological replicates for both treated and control experiments were analyzed for each species. A total protein extraction was carried out from root tissues and each sample (100 $\mu$ g protein) was labeled with one tag in the 8-plex iTRAQ ${ }^{\circledR}$ labeling kit (AB SCIEX, Foster City, CA). The treated $S$. chilense LA1958 samples were labeled with tags 113, 115, and 117 and the control samples with 114, 116, and 118. Treated 'Walter' LA3465 samples were labeled with tags 113,116 , and 118 and control samples with 114,115 , and 119. The labeled samples from the six samples of each tomato species were combined and then subjected to strong cation exchange chromatography on an isotope-coded affinity tags (ICAT) cation exchange cartridge (AB SCIEX). After a solid phase extraction (SPE) using $1-\mathrm{cm}^{3}$, 50-mg cartridges (Sep-Pak C18; Waters, Milford, MA), the multiplexed sample was first fractionated into 48 fractions by high $\mathrm{pH}$ first dimension ultraperformance liquid chromatography (UPLC) separation on a Acquity System (Waters) and then the fractions were concatenated into 16 pools. Each pool was analyzed using low $\mathrm{pH}$ reverse phase chromatography-tanden mass spectrometry on a nanoAcquity system (Waters) and a Synapt high-definition mass spectrometry (HDMS) system (Waters). Protein identification and quantification were performed using Mascot (Matrix Science, Boston, MA) search.

were denatured in $0.1 \%(\mathrm{w} / \mathrm{v})$ sodium dodecyl sulfate (SDS), reduced with $5 \mathrm{~mm}$ [tris (2-carboxyethyl)] phosphine at $60^{\circ} \mathrm{C}$ for $1 \mathrm{~h}$, and oxidized with $10 \mathrm{~mm}$ methyl methanethiosulfonate to block the exposed cysteine residues following the manufacturer’s instructions (8-plex iTRAQ ${ }^{\circledR}$ labeling kit; AB SCIEX, Foster City, CA). Then peptides were digested with trypsin (Promega, Madison, WI) at $37^{\circ} \mathrm{C}$ overnight. After digestion the samples were dried down at reduced pressure and then redissolved in $250 \mathrm{~mm}$ TEAB buffer and adjusted to $\mathrm{pH}$ 8.5. For the iTRAQ experiments, the treated S. chilense LA1958 samples were labeled with tags 113,115 , and 117 and the control samples with 114, 116, and 118. Treated 'Walter' samples were labeled with tags 113,116 , and 118 and control samples with 114, 115, and 119. Labeled proteins from the six samples of each tomato species were combined into one tube, concentrated at reduced pressure, and then loaded onto an isotope-coded affinity tags (ICAT) cation exchange cartridge 
(AB SCIEX) to exchange the buffer and to remove the SDS and the hydrolyzed unbound iTRAQ reagents from the labeled peptides.

Solid Phase EXTRACTION. iTRAQ-labeled samples processed with the ICAT cleanup kit contained an undesirable concentration of salt ( $1 \mathrm{M})$ in the elution buffer such that it would not be possible to dry and reconstitute them in a relatively small volume for loading onto the high $\mathrm{pH}$ first dimension separation system. The salt was removed through solid phase extraction using 1- $\mathrm{cm}^{3}, 50-\mathrm{mg}$ cartridges (Sep-Pak $\mathrm{C}_{18}$; Waters, Milford, MA). Each sample was dried down after the ion exchange cleanup of the ICAT kit and reconstituted in $500 \mu \mathrm{L} 0.1 \%(\mathrm{v} / \mathrm{v})$ trifluoroacetic acid (TFA). Each solid phase extraction cartridge was conditioned with three cartridge volumes $(1 \mathrm{~mL})$ of methanol and then equilibrated with five volumes of $0.1 \%$ TFA. The sample was loaded to the sorbent bed, which was then washed with five volumes of $2 \%(\mathrm{v} / \mathrm{v})$ methanol with $0.1 \%$ TFA. The sorbent bed was allowed to dry after the final wash step. The cartridge was eluted with $500 \mu \mathrm{L}$ $50 \%(\mathrm{v} / \mathrm{v})$ acetonitrile with $0.1 \%$ TFA. These samples were then dried at reduced pressure in a centrifugal concentrator and stored at $-80{ }^{\circ} \mathrm{C}$ until the first dimension separation.

HIGH PH FIRST-DIMENSION ULTRAPERFORMANCE LIQUID CHROMATOGRAPHY SEPARATION. The separation was performed using an Acquity System (Waters) coupled with a robotic fraction collector (Probot; Dionex, Sunnyvale, CA). The column used was an Acquity UPLC BEH $\mathrm{C}_{18} 1.7 \mu \mathrm{m}, 2.1 \times$ $100 \mathrm{~mm}$ (Waters). Mobile phase A was water with $20 \mathrm{~mm}$ ammonium formate, $\mathrm{pH}$ 10, and $\mathrm{B}$ was 90:10 acetonitrile: water (v/v) with $20 \mathrm{~mm}$ ammonium formate, $\mathrm{pH} 10$. A method transfer program (Guillarme et al., 2007, 2008) was used to transfer a standard high-pressure liquid chromatography high $\mathrm{pH}$ reverse phase separation to the Acquity UPLC equipment and conditions (Wang et al., 2011). Based on these calculations, a flow rate of $300 \mu \mathrm{L} \cdot \mathrm{min}^{-1}$ was used for the gradient separation. Initial conditions for the gradient were $0 \% \mathrm{~B}$, then $0 \%$ to $5 \% \mathrm{~B}$ $0.5 \mathrm{~min}, 5 \%$ to $35 \% \mathrm{~B}$ (linear) $8.5 \mathrm{~min}, 35 \%$ to $95 \%$ B $9.5 \mathrm{~min}$, $95 \%$ to $0 \%$ B $10 \mathrm{~min}$, and hold at $0 \% \mathrm{~B}$ through $14 \mathrm{~min}$.

One hundred micrograms of the multiplexed sample was injected and fractionated into 48 fractions in a 96-well plate. On injection, the autosampler triggered the fraction collector through contact closure. Fractions were collected every $14 \mathrm{~s}$ in a serpentine fashion until 48 fractions had been collected. To improve sample throughput without adversely affecting chromatographic resolution, the fractions were concatenated (Wang et al., 2011) as follows: fractions, 1, 17, and 33 were mixed to produce second dimension sample one, then 2, 18, and 34 to make sample two, then 3,19 , and 35 into sample three, and so forth until 16 fractionally concatenated second dimension fractions were produced.

LOW PH SECOND-DIMENSION REVERSE PHASE SEPARATION. Analysis of second-dimension samples proceeded according to previous analyses (Cilia et al., 2011a, 2011b; Yang et al., 2011). Dried samples were reconstituted with $25 \mu \mathrm{L}$ of $3 \%(\mathrm{v} / \mathrm{v})$ acetonitrile with $0.1 \%$ TFA. Nano-LC separation of tryptic peptides was performed with a nanoAcquity system (Waters) equipped with a Symmetry $\mathrm{C}_{18} 5 \mu \mathrm{m}, 20 \mathrm{~mm} \times 180-\mu \mathrm{m}$ trapping column and a UPLC BEH $\mathrm{C}_{18} 1.7 \mu \mathrm{m}, 15 \mathrm{~cm} \times$ $75-\mu \mathrm{m}$ analytical column (Waters). The samples, $5 \mu \mathrm{L}$ partial loop injection, were transferred to the trapping column with a $0.1 \%(\mathrm{v} / \mathrm{v})$ solution of formic acid in water at a flow rate of $7 \mu \mathrm{L} \cdot \mathrm{min}^{-1}$ for $3 \mathrm{~min}$. Mobile phase A consisted of $0.1 \%$ formic acid in water and mobile phase B consisted of $0.1 \%$ formic acid in acetonitrile. After concentration, the trapping column was subjected to a reverse flush to the analytical column and separated with a gradient of $2 \%$ to $40 \%$ mobile phase B over $90 \mathrm{~min}$ at a flow rate of $300 \mathrm{~nL} \cdot \mathrm{min}^{-1}$ followed by a 5 -min rinse with $95 \%$ of mobile phase B. The column was re-equilibrated at initial conditions for $20 \mathrm{~min}$. Column temperature was maintained at $35{ }^{\circ} \mathrm{C}$. One hundred femtomoles per microliter of $\left[\mathrm{Glu}^{1}\right]$-fibrinopeptide $\mathrm{B}$ in $25 \%$ acetonitrile with $0.1 \%$ formic acid was used as the lock mass compound and was delivered through the auxiliary pump of the LC system at a flow rate of $300 \mathrm{~nL} \cdot \mathrm{min}^{-1}$ to the reference sprayer of the NanoLockSpray source of the mass spectrometer. The eluent from the analytical column was delivered to the analytical sprayer of the same source through a PicoTip emitter (New Objective, Woburn, MA) with 10- $\mu$ m tip diameter.

Mass spectrometric analysis of tryptic peptides was performed using a Synapt high-definition mass spectrometry system (Waters). The instrument was operated in quadrupole time-of-flight (Q-TOF) V mode with a typical resolution of at least 10,000 full-width at half maximum. Analysis was conducted using positive polarity. The TOF analyzer of the mass spectrometer was externally calibrated using fragmentation of the doubly protonated monoisotopic ion of [ $\left.\mathrm{Glu}^{1}\right]$-fibrinopeptide $\mathrm{B}$ delivered through the lock mass reference sprayer. Calibration was performed over the $\mathrm{m} / \mathrm{z}$ range from 50 to 2000. Collected data were post-acquisition lock mass-corrected using the [ $\left.\mathrm{Glu}^{1}\right]$ fibrinopeptide B ion. The reference sprayer was sampled every $100 \mathrm{~s}$ for $1 \mathrm{~s}$.

Accurate mass data were obtained by liquid chromatographymass spectrometry data-dependent acquisition (LC-MS/MS DDA) as follows: MS survey scans of 1-s duration with an interscan delay of $0.02 \mathrm{~s}$ were acquired for the $\mathrm{m} / \mathrm{z}$ range from 300 to 1500 . Intensity of a single ion rising above a 60 counts per second threshold triggered MS/MS fragmentation for the ion provided the ion met charge state criteria. Charge state selection was enabled such that MS/MS data were obtained for up to four ions of charge $2^{+}, 3^{+}$, or $4^{+}$detected in the survey scans. MS/MS spectra were acquired for the $\mathrm{m} / \mathrm{z}$ range from 50 to 2000 at a scan rate of $1 \mathrm{~s}$ with an interscan delay of $0.02 \mathrm{~s}$. Charge state-dependent collision energy ramps were optimized and used to improve the quality of MS/MS spectra.

A real-time dynamic exclusion window of $45 \mathrm{~s}$ was applied to each precursor selected for fragmentation. The acquisition mode returned to MS mode when the total ion current for an MS/MS acquisition exceeded 30,000 cps or after $2.5 \mathrm{~s}$ had elapsed.

DATABase Searching AND ISObaric TAGS FOR RELATIVE AND ABSOlUte QUANTITATION QUANTITATION. Mascot Daemon (Version 2.3.2; Matrix Science, Boston, MA) was used to combine .pkl files for the 16 fractions associated with each sample and to query them against an ITAG 2.3 tomato protein database [downloaded on 16 Sept. 2011 (Bombarely et al., 2011)]. Trypsin was selected as the enzyme with one missed cleavage allowed. iTRAQ labeling of the amino terminus and the epsilon amine of lysine were set as fixed modifications, whereas iTRAQ labeling of tyrosine, oxidation of methionine, S-methylation of cysteine, and deamidation of asparagine and glutamine were set as variable modifications. Peptide charge was set to $2+, 3+$, and $4+$. Precursor mass tolerance was set to $0.05 \mathrm{Da}$, whereas fragment tolerance was set to $0.1 \mathrm{Da}$. The instrument type selected was nano-electrospray quadripole TOF. It was required 
that each protein quantification reported be based on at least two confidently quantified peptides.

ANALYSIS AND CHARACTERIZATION OF DIFFERENTIAL PROTEIN EXPRESSION. The data were normalized using the method of summed intensities and intensity weighting was applied to minimize background contributions from the "weaker" spectra. Peptides with no quantification, absence of two reporter ions in three biological replicate samples, and peptides missing iTRAQ reagent labels in either treated or control samples were removed. In the iTRAQ data, there were some peptides missing only one reporter ion of the six samples (three replicates each from treated and control treatments). The mean value from the other two reporter ions within the three treated or control replicates was used for the missing reporter ion when a protein was identified with multiple peptides, but the peptide was removed in the case in which only one peptide was identified to a protein, and the protein was not analyzed. Additionally, peptides shared among related but distinct proteins or peptides in which the spectrum was also matched to a different protein with an unrelated peptide sequence were not used in quantification. Remaining peptides were included as contributing factors to protein quantification (Boehm et al., 2007).

In proteomics analysis, lognormal transformation $\left(\log _{2}\right)$ has been applied to iTRAQ data sets to generate near-normally distributed data for protein quantification analysis (Boehm et al., 2007; Bowden et al., 2012). In this study, the normalized peak intensities of reporter ions of constituent peptides were $\log _{2}$ transformed, and a data set of $\log _{2}$ fold was constructed, where $\log _{2}$ fold value $=\log _{2}$ (ion intensity) of the individual iTRAQ tag subtracted by the means of the three control replicates. Then $\log _{2}$ fold values from all constituent peptides were subjected to $t$ test (the general linear model procedure) followed by false discovery rate corrections to test the statistical significant difference of the respective protein between the treated and control samples (three replicates each).

Proteins passing the two steps of statistical tests $(P \leq 0.05)$ were selected as members that were significantly altered in abundance by the dehydration treatment. Then the $\log _{2}$ fold values were back-transformed through antilogarithmic transformation to yield the "fold change" of protein expression. Induced proteins in the treated samples have a fold change value, which equals the antilogarithm value, and repressed proteins have a fold value, which is the inverse of the antilogarithm value. Identified proteins were classified into "cellular function" groups based on their putative molecular functions in various biological processes. Data analysis was performed separately for each tomato species, and the identified proteins within each function group were compared between the two species to identify those associated with dehydration tolerance. Statistical procedures were performed using SAS (Version 9.3; SAS Institute, Cary, NC).

\section{Results and Discussion}

\section{The dehydration-induced root proteomes in $S$. chilense and 'Walter'}

In S. chilense LA1958, 170 proteins were identified, 106 $(62 \%)$ proteins were repressed, and $64(38 \%)$ proteins were induced (Supplemental Table 1). In 'Walter' LA3465, 130 proteins displayed significant changes in abundance on dehydration treatment $(P \leq 0.05), 104(80 \%)$ proteins were repressed, and $26(20 \%)$ were induced (Supplemental Table 2). Those identified proteins were classified into 11 groups: Group 1, stress proteins; Group 2, gene expression; Group 3, nascent protein processing and protein folding; Group 4, protein degradation; Group 5, carbohydrate metabolism; Group 6, amino acid and nucleotide metabolism; Group 7, lipid metabolism; Group 8, ATPases; Group 9, signal transduction; Group 10, cell cycle and cellular structure; and Group 11, ungrouped proteins (Fig. 2).

\section{Changes of protein expression and the role in tolerance to dehydration stresses}

STRESS Proteins (Group 1). In the dehydration-treated tomato roots, several proteins directly associated with water deficit stress were identified. In S. chilense LA1958, a late embryogenesis abundant protein (LEA) (1.34-fold) and an abscisic acid, stress and ripening induced (ASR) protein (1.99-fold) were induced. In 'Walter' LA3465, a dehydrin
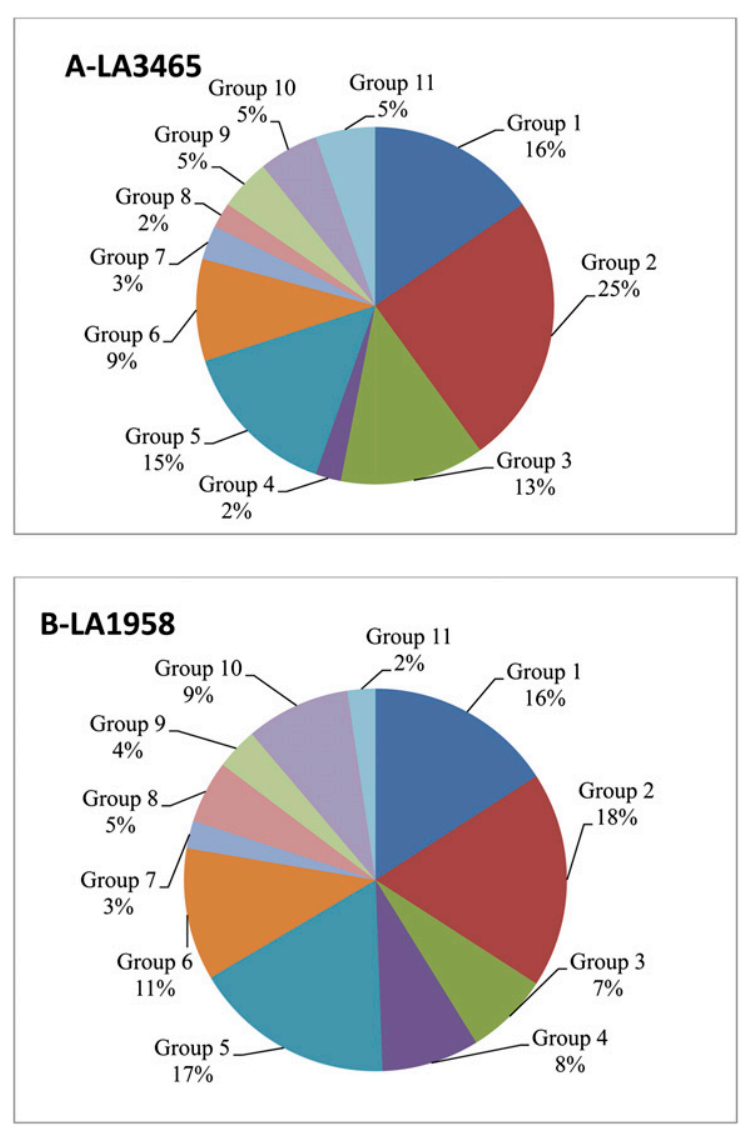

Fig. 2. The functional classification of dehydration-responsive root proteins in Solanum lycopersicum 'Walter' and Solanum chilense. Dehydrationresponsive proteins in roots were identified using isobaric tags for relative and absolute quantitation (iTRAQ) followed by statistical analysis using SAS (Version 9.3; SAS Institute, Cary, NC). Proteins showing significant changes in abundance between treated and control samples $[P \leq 0.05$ in $t$ test with false discovery rate (FDR) corrections] were placed into 11 subgroups based on their putative molecular functions in various biological processes: Group $1=$ stress proteins, Group 2 = gene expression, Group 3 = nascent protein processing and protein folding, Group $4=$ protein degradation, Group $5=$ carbohydrate metabolism, Group 6 = amino acid and nucleotide metabolism, Group $7=$ lipid metabolism, Group $8=$ ATPases, Group $9=$ signal transduction, Group $10=$ cell cycle and cellular structure, and Group $11=$ ungrouped proteins. The distribution of identified proteins in each group is indicated as a percentage in tomato 'Walter' LA3465 (A) and S. chilense LA1958 (B). 
(1.55-fold) and a water-stress inducible protein 3 (2.36-fold) were induced.

Dehydration proteins (dehydrins) accumulate in plants under dehydration conditions (Close, 1997; Close and Lammers, 1993) and significantly elevated levels of dehydrin gene expression is an indication of low temperature and drought stress in barley [Hordeum vulgare (Tommasini et al., 2008)]. The LEA proteins are extremely hydrophilic proteins, they play active roles in cellular defense mechanisms against various dehydration-associated stresses, and these proteins are thought to participate in repair pathways for dehydration-induced cellular damage (Olvera-Carrillo et al., 2010; Xiong et al., 2002). Their intracellular accumulation is highly associated with acquisition of desiccation tolerance (Hand et al., 2011; Hoekstra et al., 2001). Elevated accumulation of these hydrophilic proteins such as LEA or dehydrins is consistent with our implicit assumption that dehydration was the primary stress occurring in tomato roots as a result of the treatment.

ASRs are induced by water deficit in tomato and their wild relative species (Amitai-Zeigerson et al., 1995; Frankel et al., 2003, 2006; Maskin et al., 2007, 2008). These highly hydrophilic proteins play a very important role in adaptation to extreme drought in wild tomato species including S. chilense (Fischer et al., 2011). In the tolerant $S$. chilense LA1958, the ASR protein was also induced by the dehydration treatment, which further validated the role of this protein in conferring tolerance to water deficit stress.

Plasma membrane intrinsic aquaporin proteins (PIPs) are primary channels, which facilitate water uptake in plant cells. Some root PIPs may regulate water transport across roots such that transpirational demand is matched by root water transport capacity (Vandeleur et al., 2009). Lower root PIP activity has been found to be associated with higher tolerance to dehydration stress in grape (Vitis vinifera) (Vandeleur et al., 2009) and Carrizo citrange [Citrus sinensis $\times$ Poncirus trifoliata (Rodríguez-Gamir et al., 2011)]. In S. chilense one PIP was repressed (-1.35-fold), whereas two of those proteins were induced in 'Walter' LA3465 (1.17- to 1.35-fold). These results indicate that root PIPs plays an important role in plant tolerance to water deficit. The repression of PIP may be associated with less water loss through transpiration through stomata, which is an important trait of plant tolerance to dehydration (Schroeder et al., 2001).

Oxidative stress is a major secondary cellular stress provoked by various adverse conditions including water deficit. Antioxidant enzymes, by controlling the cellular level of reactive oxidative species (ROS), not only play major roles in oxidative stress metabolism, but they also regulate oxidative signal transducer in abscisic acid (ABA) and drought stress signaling (Miao et al., 2006). Thus, the antioxidant capacity significantly affects the degree of plant tolerance against the primary stress. On dehydration treatments, different antioxidant systems were activated in the two tomato species. Superoxide dismutase was induced in S. chilense LA1958 (1.67-fold) but repressed in 'Walter' LA3465 (-1.42-fold). In contrast, a monodehydroascorbate reductase protein (NADH)-like protein was induced in 'Walter' LA3465 (1.39-fold) but repressed in S. chilense LA1958 (-1.33-fold). Glutathione S-transferases (1.18- to 1.22-fold in LA3465, 1.39- to 1.57-fold in S. chilense LA1958) and peroxidase (1.24-fold in LA3465, 1.41-fold in $S$. chilense LA1958) were induced in both species but more strongly in the tolerant $S$. chilense. Ferredoxin-NADP reductase was repressed in 'Walter' LA3465 (-1.26-fold), and catalase was repressed in S. chilense LA1958 (-3.17-fold). Glutathione peroxidase (1.36-fold), cytochrome b5 (2.08-fold), and thioredoxin (2.18-fold) were induced only in S. chilense LA1958.

Polyphenol oxidases (PPO) catalyze the reaction for the formation of cytotoxic orthoquinones. In the dehydration treated S. chilense LA1958, PPO was repressed (-1.93-fold), but the same protein was induced (2.60-fold) together with two laccases (a type of PPO) (2.73- to 3.12-fold) in 'Walter' LA3465. A previous study showed that transgenic tomato plants containing antisense PPO DNA in which PPO activity was repressed were more tolerant to water deficit stress compared with nontransgenic and transgenic plants overexpressing PPO (Thipyapong et al., 2004). This result agrees with the repression of PPO in the tolerant $S$. chilense LA1958 but the induction in the sensitive 'Walter' LA3465.

GeNe EXPRession (Group 2). Proteins in this group are involved in gene transcription and post-transcriptional modification and protein translation. Sixteen proteins were identified that would affect formation of mature transcripts. A transcription factor protein known as the basic leucine zipper was induced (1.56-fold) and a nuclear matrix protein with putative transcription factor function was repressed $(-1.45$-fold $)$ in 'Walter'LA3465. In S. chilense LA1958, helicase sen1 was repressed (-2.44-fold). Reduction of helicase expression was considered as a proactive stress-tolerance mechanism because it may function to downregulate pathways whose functioning is detrimental during stress conditions (Owttrim, 2006).

A major difference between the two tomato species occurred in proteins with a role in post-transcriptional regulation. In S. chilense LA1958, small nuclear ribonucleoprotein (snRNPs) LSM8 (2-fold) and heterogeneous nuclear ribonucleoprotein (hnRNPs) A3 (1.24-fold) were induced. The snRNPs and hnRNPs are components of pre-mRNA regulatory networks and elevated expression level of these proteins could affect mature mRNA production in the tolerant species, which play a key role in the cellular responses triggered by stresses (Denegri et al., 2001; Zhang et al., 2011).

Protein translation is regulated at the levels of initiation, elongation, and termination (Mahoney et al., 2009; Scheper et al., 2007). Under stress circumstances, reprogramming of the process allows immediate and selective changes in protein levels to trigger defense responses (Holcik and Sonenberg, 2005; Yamasaki and Anderson, 2008). In tomato, dehydration affected expression of ribosomal subunits, translation initiation factors, translation elongation factor, and other proteins forming the protein translation complex. All these proteins were repressed in 'Walter' LA3465, and the majority of the proteins were also repressed in the tolerant $S$. chilense LA1958. Such changes could lead to arrest or repression of protein translation. Together with the reduced amino acid regeneration (described in the metabolic group), global protein biosynthesis should be suppressed by the dehydration treatment, which can be considered as an adaptive response to survive under adverse conditions to save energy (Hinnebusch, 1994; Mahoney et al., 2009; Muñoz and Castellano, 2012).

In addition to being the primary structural constituents of protein translation machinery, many ribosomal proteins have secondary roles such as providing safeguard against perturbations to ribosome function and accuracy and efficiency of protein translation (Amarnath et al., 2012; De Wilde et al., 1975). In S. chilense LA1958, two elongation factor beta-1 proteins (1.23- to 1.45 -fold) and a $40 \mathrm{~S}$ ribosomal protein S17 
(1.44-fold) were induced. These proteins are involved in controlling translation fidelity (Carr-Schmid et al., 1999; Simitsopoulou et al., 1999), and therefore the tolerant S. chilense LA1958 may have activated a system to safeguard the accuracy of protein translation under dehydration conditions. The ribosomal protein L12 (1.59-fold) was also induced in $S$. chilense LA1958, which uses a distinct nuclear import pathway that may contribute to a mechanism for regulating ribosome synthesis and/or maturation (Plafker and Macara, 2002).

NASCENT PRotein PRocessing, LOCALIZATION, AND PROTEIN FOLDING (Group 3). Nascent proteins emerging from the ribosome must go through several procedures of posttranslational modification and folding to be delivered to the correct subcellular organelles. This process is mediated by chaperones, cochaperones, and other protein homeostasis factors. T-complex protein is an important cochaperone that assists the folding of proteins including actins and tubulins, on ATP hydrolysis, and this protein was repressed in both species (-2.40-fold in $S$. chilense LA1958, -1.20-fold in 'Walter' LA3465). Prefoldin is the only cochaperone that promotes proper folding of nascent proteins without the use of ATP (Pockley, 2005; Vainberg et al., 1998). Prefoldin protein was induced in $S$. chilense LA1958 (2.47-fold) but repressed in 'Walter' LA3465 (-1.17-fold). An increase of this protein only in the tolerant $S$. chilense suggests that this protein plays an essential role in protein folding under dehydration circumstances where energy regeneration (ATP) could be significantly reduced (see the metabolic protein group).

Other chaperones and protein foldases in the rough endoplasmic reticulum organelles include protein disulfide isomeras (Hatahet and Ruddock, 2009; Wilkinson and Gilbert, 2004) and peptidyl-prolyl cis-trans isomerase (Ahn et al., 2010; Schönbrunner and Schmid, 1992). The protein disulfide isomerase was induced in $S$. chilense LA1958 (1.77-fold) but repressed in 'Walter' LA3465 (-1.12-fold).

Plant mitochondrial proteome is comprised of $\approx 20$ proteins that are translated within the organelle (Levings and Brown, 1989) and a vast number of nuclear-encoded proteins (up to 2000), which are synthesized in cytoplasm as pre-peptides tagged by N-terminal signal sequences (Millar et al., 2005). Those cytosolic translated proteins are imported into the intermembrane space of the mitochondrion through channels such as the translocase of the outer membrane (TOM) complex. Inside the mitochondria, mitochondrial processing peptidase (MPP) can recognize and cleave off the signal peptides before those proteins are delivered to various subcompartments within the organelle. MPP is also responsible for the modification of mitochondrion-translated pre-polypeptides. Therefore, mitochondrial proteomes are greatly affected by those channel proteins and MPP.

Proteins involved in those two processes were affected by dehydration in the two tomato species. Tom40 is a central subunit of the TOM complex; it assists the movement of protein precursors into mitochondria and thus has an essential role for import of protein precursors into the organelle (Ahting et al., 2001; Gabriel et al., 2003). Tom40 was repressed in $S$. chilense LA1958 (-1.33-fold) and in 'Walter' LA3465 (-1.35-fold). Two proteins for the MPP were also repressed in $S$. chilense LA1958 (-1.77- to -1.93-fold) and in 'Walter' LA3465 (-1.35to -1.37 -fold). These results indicate dehydration affected protein expression involved in the processes of protein import into mitochondria and then converting precursor proteins into mature forms. Because this occurred in both tomato species, it is not directly related to the tolerance properties to dehydration.

Proteolysis (Group 4). The ubiquitin-proteasome system is responsible for the majority of selective protein degradation in nucleus and cytosol (Vierstra, 1993), and the ubiquitindependent protein degradation is activated to remove nonfunctional and potentially harmful polypeptides thus enhancing tolerance to stresses (Lyzenga and Stone, 2012; Xu et al., 2001; Zhang et al., 2007, 2010). Ubiquitin directs proteins to proteasomes for recycling (Hanna et al., 2007), and this protein was induced to a significantly higher level (1.96-fold) in the tolerant $S$. chilense LA1958. Several proteins for the $26 \mathrm{~S}$ proteasome were repressed in both species. Such disparity between ubiquitin and proteasomes makes it a very intriguing question as to whether this protein degradation pathway was induced or suppressed in the two tomato species.

Other proteinases include the endo- and carboxy-peptidases localized in vacuoles and aminopeptidases in the cytoplasm (Huffaker, 1990). Several of those proteins (subtilisin-like protease, -1.44-fold; aspartic proteinase, -1.54-fold; aspartyl aminopeptidase-like protein, -1.43 -fold) were repressed in $S$. chilense LA1958, but no significant changes were found in 'Walter' LA3465. Additionally, two proteinase inhibitors (chymotrypsin inhibitors, 1.51- to 1.78-fold; and a proteinase inhibitor II, 2.21-fold) were induced in S. chilense LA1958 but not in LA3465. Results presented here suggest that the two tomato species may activate different mechanisms to control protein turnover in response to dehydration.

Proteins inVolved in VARIOUS Biological Metabolic PATHWAYS (Groups 5, 6, 7, AND 8). Both energy molecules and their precursor molecules are essential for sustaining cellular activities and are provided through various catabolic or anabolic pathways. In the dehydration-treated tomato roots, one of the most dramatic changes was the repression of enzymes in glycolysis, pentose phosphate pathways, gluconeogenesis, and ATP synthases for the regeneration of ATP in both species. Furthermore, enzymes for the biosynthesis of amino acids (lysine, leucine, serine, aromatic amino acids, histine, methionine, and quaternary ammonium compounds) and nucleotides (purine) were also repressed in one or both tomato species and no enzymes in these pathways were induced. These results indicate that dehydration had led to a significant decline of many cellular reactions.

Proteins in the oxidative phosphorylation pathway were affected differentially in the two species. In $S$. chilense LA1958, mitochondrial F0 ATP synthase D chain (1.24-fold), adenylate kinase (1.39-fold), cytochrome c oxidase subunit $\mathrm{Vb}$ (1.39-fold), and a blue copper protein (2.89-fold) were induced. In contrast, the same group of proteins was repressed in 'Walter' LA3465. These proteins are involved in oxidative phosphorylation pathway. In a study on cultivar-specific response of wheat, it was found that mitochondria from droughtsensitive genotypes had lower oxidative phosphorylation efficiency after dehydration and rewatering, whereas the drought-tolerant 'Katya' mitochondria showed higher phosphorylation rates (Vassileva et al., 2009). Taken together, higher oxidative phosphorylation activity seems to be associated with tolerance to water deficit stress.

The two tomato species differed in lipid metabolism, which plays a key role in membrane stability, thus being very important for tolerance to environmental stress (Graumann 
Table 1. The identity and dehydration-induced abundance changes of root proteins in Solanum lycopersicum 'Walter' LA3465 and wild species Solanum chilense LA1958. ${ }^{\mathrm{z}}$

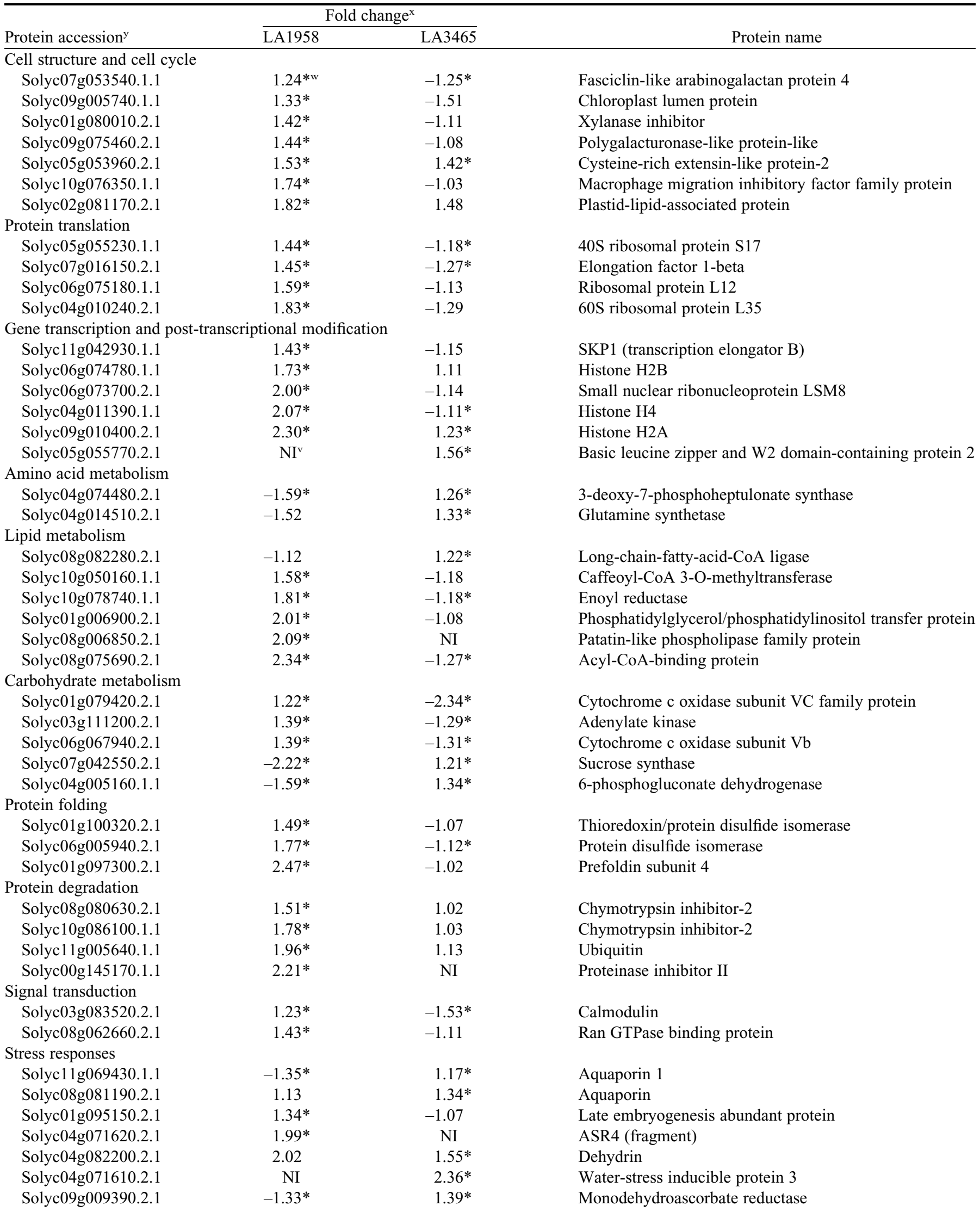


Table 1. Continued.

\begin{tabular}{|c|c|c|c|}
\hline \multirow[b]{2}{*}{ Protein accession ${ }^{y}$} & \multicolumn{2}{|c|}{ Fold change $^{\mathrm{x}}$} & \multirow[b]{2}{*}{ Protein name } \\
\hline & LA1958 & LA3465 & \\
\hline Solyc12g056230.1.1 & $1.36^{*}$ & -1.11 & Glutathione peroxidase \\
\hline Solyc06g009020.2.1 & $1.39 *$ & 1.12 & Glutathione S-transferase \\
\hline Solyc $10 \mathrm{~g} 084400.1 .1$ & $1.57 *$ & $1.17^{*}$ & Glutathione S-transferase \\
\hline Solyc01g067740.2.1 & $2.08 *$ & $-1.25 *$ & Superoxide dismutase \\
\hline Solyc07g008130.2.1 & $2.89 *$ & $-1.23 *$ & Blue copper protein \\
\hline Solyc07g042550.2.1 & NI & $1.38^{*}$ & Polyphenol oxidase \\
\hline Solyc05g052340.2.1 & $\mathrm{NI}$ & $2.73 *$ & Laccase \\
\hline Solyc06g082240.2.1 & NI & $3.12 *$ & Laccase-13 \\
\hline Solyc01g010750.2.1 & $1.31 *$ & -1.09 & Stress responsive protein \\
\hline Solyc09g005500.2.1 & $1.40^{*}$ & $-1.50 *$ & Major latex-like protein \\
\hline Solyc09g005400.2.1 & $1.52 *$ & -1.33 & Major latex-like protein \\
\hline Solyc09g090980.2.1 & $1.59 *$ & $1.53 *$ & Major allergen Mal d 1 \\
\hline Solyc02g081140.2.1 & $1.59 *$ & 1.02 & UBX domain-containing protein \\
\hline Solyc03g006680.2.1 & $1.69 *$ & -1.09 & Universal stress protein \\
\hline Solyc02g088260.2.1 & $1.73 *$ & -1.09 & Latex abundant protein 1 \\
\hline \multicolumn{4}{|l|}{ Other proteins } \\
\hline Solyc06g050980.2.1 & $1.35^{*}$ & 1.11 & Ferritin \\
\hline Solyc01g102310.2.1 & $2.56^{*}$ & $-1.18^{*}$ & Unknown protein \\
\hline Solyc02g084850.2.1 & NI & $7.25^{*}$ & Unknown protein \\
\hline
\end{tabular}

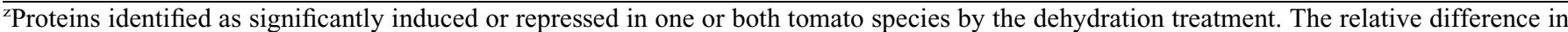
abundance of each protein, measured by the intensity of its constituent peptides, was compared between treated and control samples within each species. In every case. at least one of the two species has passed the $t$ test [general linear model (GLM)] with false discovery rate (FDR) corrections $(P \leq 0.05)$. Statistical analyses were performed using SAS (Version 9.3; SAS Institute, Cary, NC).

yProtein accession number in the ITAG Protein database (release 2.3 on 26 Apr. 2011; Sol Genomics Network, Boyce Thompson Institute, Ithaca, NY).

${ }^{\mathrm{x}}$ The fold change value for each protein is the ratio of the protein abundance level between treated and control samples within each species. For example, a value of 2.0 represents a 2 -fold increase, whereas -2.0 represents a 2 -fold decrease from treated to control conditions.

${ }^{w}$ Proteins showing significant changes in abundance in treated roots vs. control condition within the respective species $(P \leq 0.05$ with $5 \%$ FDR correction). Proteins without the asterisk had no significant change from treated to control samples.

vProteins not identified in the respective species.

et al., 1996; Mou et al., 2000). In S. chilense LA1958, phosphatidylglycerol/phosphatidylinositol transfer protein (PG/PI-TP) (2.01-fold), acyl-CoA-binding protein (2.34-fold), enoyl reductase (1.81-fold), and patatin-like phospholipase (2.09-fold) were all induced. PG/PI-TP catalyzes the intermembrane transfer of phosphatidylglycerol and phosphatidylinositol and participates in membrane biogenesis and regulation of intracellular fatty acid pools. Acyl-CoA-binding proteins bind to long-chain acyl-CoA esters and phospholipids, and they are involved in diverse cellular functions including acyl-CoA homeostasis and stress tolerance (Xiao and Chye, 2011). Phospholipases catalyze hydrolysis of phospholipids into fatty acids in lipid signaling, which is an important response mechanism to abiotic stresses (water and temperature stresses) in plants (Bargmann and Munnik, 2006; Tuteja and Sopory, 2008; Xiong et al., 2002). In 'Walter' LA3465, the enoyl reductase (-1.18-fold) and acyl-CoA-binding protein $(-1.15$ fold) were repressed, but a long-chain-fatty-acid-CoA ligase (1.22-fold) was induced. This latter enzyme activates betaoxidation of fatty acids to produce acetyl-CoA, which feeds to the citric acid cycle, and other cellular processes. Therefore, the mechanism activated in 'Walter' LA3465 was more strongly directed toward the catabolism of fatty acids.

Signal Transduction (Group 9). Signal transduction network consists of elements for the perception of stress signals, the first $\left(\mathrm{Ca}^{2+}\right)$ and second messengers (such as ROS, ABA, brassinosteroids, ethylene, phospholipids), intermediate messenger (calmodulin), and transcription factors, which activate expression of stress-responsive genes (Xiong et al., 2002). On dehydration treatment, calmodulin was induced in $S$. chilense LA1958 (1.23-fold) but repressed in 'Walter' LA3465 (-1.53fold). A study on Arabidopsis thaliana showed that gene expression and activity of calmodulin enhanced salt and drought tolerance by increasing ABA sensitivity (Xu et al., 2011). The 14-3-3 protein is an intermediate messenger in ABA- and brassinosteroid-signal transduction pathways (Bai et al., 2007; Schoonheim et al., 2007; Yan et al., 2004). The protein was repressed (-1.19-fold) in 'Walter' LA3465 but induced (1.34fold, but not statistically significant) in S. chilense LA1958. These results suggest that calmodulin and 14-3-3 protein play a critical role in activating dehydration tolerance in tomato. Additionally, the Ran GTPase binding protein (1.43-fold) 
was induced in S. chilense LA1958 but not in LA3465. The 1-aminocyclopropane-1-carboxylate oxidase 1 in the ethylene biosynthesis pathway was repressed in S. chilense LA1958 (-2.22-fold), which was not found in 'Walter' LA 3465.

Cell CyCle progression (Group 10). Cell cycle progression is affected by the following three cellular activities: chromosome duplication, which involves histone proteins and DNA doubling, cytoskeleton protein regeneration (tubulin and actin), and cell wall formation. Cell skeleton proteins (actins and tubulins) were repressed in both tomato species. Proteins affecting cell cycle progression (histone-binding protein RBBP7, -1.53-fold; ADP-ribosylation factor, -1.52-fold) were repressed in $S$. chilense LA1958. Repression of these proteins may result in low cell cycle activity and slow cell production, which occurs under water deficit conditions (Schuppler et al., 1998).

\section{Conclusions}

The dehydration-induced changes in tomato root proteome and the associated molecular consequences can be summarized as follows: 1) When tomato plants were exposed to dehydration stress, proteins involved in the biological activities for the catabolism of carbohydrates and anabolism of amino acids and nucleotides were repressed. Proteins in oxidative phosphorylation and lipid metabolic pathways were regulated differentially in the two tomato species with contrasting dehydration tolerance. 2) Proteins for post-transcriptional regulation of gene expression were induced in the tolerant species and protein translation was repressed in both species. 3) Calmodulin was induced in the tolerant tomato species but repressed in the susceptible cultivar. 4) Proteins for folding nascent and denatured proteins and proteins mediating protein processing and localization in the ER and mitochondrial organelles were affected differently in the two species. Prefoldin that promotes protein folding without the use of ATP was induced only in the tolerant species. 5) The two tomato species activated different antioxidant enzymes in response to the dehydration treatment. 6) Ubiquitin was induced only in the tolerant species. Proteasomes were repressed in both species, so there could be a very complex protein turnover mechanism in the two species.

In summary, this study has identified proteins that are associated with tolerance to dehydration in tomato. Table 1 lists proteins that were induced in one or both tomato species. This information may be useful when selecting candidate proteins (genes) as markers for dehydration tolerance or developing tolerant tomato genotypes through overexpression or suppressing of specific proteins.

\section{Literature Cited}

Ahn, J.C., D.W. Kim, Y.N. You, M.S. Seok, J.M. Park, H. Hwang, B.G. Kim, S. Luan, H.S. Park, and H.S. Cho. 2010. Classification of rice (Oryza sativa L. japonica nipponbare) immunophilins (FKBPs, CYPs) and expression patterns under water stress. BMC Plant Biol. 10:253.

Ahting, U., M. Thieffry, H. Engelhardt, R. Hegerl, W. Neupert, and S. Nussberger. 2001. Tom 40 , the pore-forming component of the protein-conducting TOM channel in the outer membrane of mitochondria. J. Cell Biol. 153:1151-1160.

Amarnath, S., T. Kawli, S. Mohanty, N. Srinivasan, and V. Nanjundiah. 2012. Pleiotropic roles of a ribosomal protein in Dictyostelium discoideum. PLoS One 7:e30644.
Amitai-Zeigerson, H., P.A. Scolnik, and D. Bar-Zvi. 1995. Tomato Asr 1 mRNA and protein are transiently expressed following salt stress, osmotic stress and treatment with abscisic acid. Plant Sci. 110:205-213.

Bai, M.Y., L.Y. Zhang, S.S. Gampala, S.W. Zhu, W.Y. Song, K. Chong, and Z.Y. Wang. 2007. Functions of OsBZR1 and 14-3-3 proteins in brassinosteroid signaling in rice. Proc. Natl. Acad. Sci. USA 104:13839-13844.

Bargmann, B.O. and T. Munnik. 2006. The role of phospholipase D in plant stress responses. Curr. Opin. Plant Biol. 9:515-522.

Bartels, D. and S. Erik. 2004. Molecular responses of higher plants to dehydration, p. 9-38. In: Hirt, H. and K. Shinozaki (eds.). Plant responses to abiotic stresses: Topics in current genetics. Vol. 4. Springer-Verlag, Berlin/Heidelberg, Germany.

Bengough, A.G., B.M. McKenzie, P.D. Hallett, and T.A. Valentine. 2011. Root elongation, water stress, and mechanical impedance: A review of limiting stresses and beneficial root tip traits. J. Expt. Bot. 62:59-68.

Boehm, A.M., S. Pütz, D. Altenhöfer, A. Sickmann, and M. Falk. 2007. Precise protein quantification based on peptide quantification using iTRAQ ${ }^{\text {TM }}$. BMC Bioinformatics 8:214.

Bombarely, A., N. Menda, I.Y. Tecle, R.M. Buels, S. Strickler, T. Fischer-York, A. Pujar, J. Leto, J. Gosselin, and L.A. Mueller. 2011. The Sol Genomics Network (solgenomics.net): Growing tomatoes using Perl. Nucleic Acids Res. 39:D1149-D1155.

Bowden, P., T. Thavarajah, P. Zhu, M. McDonell, H. Thiele, and J.G. Marshall. 2012. Quantitative statistical analysis of standard and human blood proteins from liquid chromatography, electrospray ionization, and tandem mass spectrometry. J. Proteome Res. 11:2032-2047.

Carr-Schmid, A., L. Valente, V.I. Loik, T. Williams, L.M. Starita, and T.G. Kinzy. 1999. Mutations in elongation factor 1beta, a guanine nucleotide exchange factor, enhance translational fidelity. Mol. Cell. Biol. 19:5257-5266.

Chetelat, R.T., R.A. Pertuze, L. Faundez, E.B. Graham, and C.M. Jones. 2009. Distribution, ecology and reproductive biology of wild tomatoes and related nightshades from the Atacama desert region of northern Chile. Euphytica 167:77-93.

Cilia, M., C. Tamborindeguy, T. Fish, K. Howe, T.W. Thannhauser, and S. Gray. 2011a. Genetics coupled to quantitative intact proteomics links heritable aphid and endosymbiont protein isoform expression to polerovirus transmission. J. Virol. 85:2148-2166.

Cilia, M., K. Howe, T. Fish, D. Smith, J. Mahoney, C. Tamborindeguy, J. Burd, T.W. Thannhauser, and S. Gray. 2011b. Biomarker discovery from the top down: Digital protein biomarkers for virus transmission by insects discovered by coupling genetics and 2-D DIGE. Proteomics 11:2440-2458.

Close, T.J. 1997. Dehydrins: A commonality in the response of plants to dehydration and low temperature. Physiol. Plant. 100:291-296.

Close, T.J. and P.J. Lammers. 1993. An osmotic stress protein of cyanobacteria is immunologically related to plant dehydrins. Plant Physiol. 101:773-779.

De Carvalho, M.H.C. 2008. Drought stress and reactive oxygen species: Production, scavenging and signaling. Plant Signal. Behav. 3:156-165.

Degenkolbe, T., P.T. Do, E. Zuther, D. Repsilber, D. Walther, D.K. Hincha, and K.I. Köhl. 2009. Expression profiling of rice cultivars differing in their tolerance to long-term drought stress. Plant Mol. Biol. 69:133-153.

Denegri, M., I. Chiodi, M. Corioni, F. Cobianchi, S. Riva, and G. Biamonti. 2001. Stress-induced nuclear bodies are sites of accumulation of pre-mRNA processing factors. Mol. Biol. Cell 12:35023514.

De Wilde, M., T. Cabezón, R. Villarroel, A. Herzog, and A. Bollen. 1975. Cooperative control of translation fidelity by ribosomal proteins in Escherichia coli. I. Properties of ribosomal mutants whose resistance to neamine is the cumulative effect of two distinct mutations. Mol. Gen. Genet. 142:19-33. 
Fischer, I., L. Camus-Kulandaivelu, F. Allal, and W. Stephan. 2011. Adaptation to drought in two wild tomato species: The evolution of the Asr gene family. New Phytol. 190:1032-1044.

Ford, K.L., A. Cassin, and A. Bacic. 2011. Quantitative proteomic analysis of wheat cultivars with differing drought stress tolerance. Frontiers Plant Sci. 2:44.

Frankel, N., F. Carrari, E. Hasson, and N.D. Iusem. 2006. Evolutionary history of the Asr gene family. Gene 378:74-83.

Frankel, N., E. Hasson, N.D. Iusem, and M.S. Rossi. 2003. Adaptive evolution of the water stress induced gene Asr2 in Lycopersicon species dwelling in arid habitats. Mol. Biol. Evol. 20:1955-1962.

Fulda, S., S. Mikkat, H. Stegmann, and R. Horn. 2011. Physiology and proteomics of drought stress acclimation in sunflower (Helianthus annuus L.). Plant Biol. 13:632-642.

Gabriel, K., B. Egan, and T. Lithgow. 2003. Tom40, the import channel of the mitochondrial outer membrane, plays an active role in sorting imported proteins. EMBO J. 22:2380-2386.

Graumann, P., K. Schroeder, R. Schmid, and M.A. Marahiel. 1996. Cold shock stress-induced proteins in Bacillus subtilis. J. Bacteriol. 178:4611-4619.

Guillarme, D., V. Meyer, and J.L. Veuthey. 2008. Method transfer in HPLC. LC-GC Europe 21:322-327.

Guillarme, D., D. Nguyen, S. Rudaz, and J.L. Veuthey. 2007. Method transfer for fast liquid chromatography in pharmaceutical analysis: Application to short columns packed with small particle. Part I: Isocratic separation. Eur. J. Pharm. Biopharm. 66:475-482.

Hajheidari, M., A. Eivazi, B.B. Buchanan, J.H. Wong, I. Majidi, and G.H. Salekdeh. 2007. Proteomics uncovers a role for redox in drought tolerance in wheat. J. Proteome Res. 6:1451-1460.

Hand, S.C., M.A. Menze, M. Toner, L. Boswell, and D. Moore. 2011. LEA proteins during water stress: Not just for plants anymore. Annu. Rev. Physiol. 73:115-134.

Hanna, J., A. Meides, D.P. Zhang, and D. Finley. 2007. An ubiquitin stress response induces altered proteasome composition. Cell 129:747-759.

Harb, A., A. Krishnan, M.M.R. Ambavaram, and A. Pereira. 2010. Molecular and physiological analysis of drought stress in Arabidopsis reveals early responses leading to acclimation in plant growth. Plant Physiol. 154:1254-1271.

Hatahet, F. and L.W. Ruddock. 2009. Protein disulfide isomerase: A critical evaluation of its function in disulfide bond formation. Antioxid. Redox Signal. 11:2807-2850.

Hinnebusch, A.G. 1994. Translational control of GCN4: An in vivo barometer of initiation-factor activity. Trends Biochem. Sci. 19:409-414.

Hoagland, D.R. and D.I. Arnon. 1950. The water culture method for growing plants without soil. California Agr. Expt. Sta. Circ. 347.

Hoekstra, F.A., E.A. Golovina, and J. Buitink. 2001. Mechanisms of plant desiccation tolerance. Trends Plant Sci. 6:431-438.

Holcik, M. and N. Sonenberg. 2005. Translational control in stress and apoptosis. Nat. Rev. Mol. Cell Biol. 6:318-327.

Huffaker, R.C. 1990. Proteolytic activity during senescence of plant. New Phytol. 116:199-223.

Kültz, D. 2003. Evolution of the cellular stress proteome: From monophyletic origin to ubiquitous function. J. Exp. Biol. 206: 3119-3124.

Levings, C.S., III and G.G. Brown. 1989. Molecular biology of plant mitochondria. Cell 56:171-179.

Lyzenga, W.J. and S.L. Stone. 2012. Abiotic stress tolerance mediated by protein ubiquitination. J. Expt. Bot. 63:599-616.

Mahoney, S.J., J.M. Dempsey, and J. Blenis. 2009. Cell signaling in protein synthesis ribosome biogenesis and translation initiation and elongation. Prog. Mol. Biol. Trans. Sci. 90:53-107.

Maskin, L., N. Frankel, G. Gudesblat, M.J. Demergasso, L.I. Pietrasanta, and N.D. Iusem. 2007. Dimerization and DNA-binding of ASR1, a small hydrophilic protein abundant in plant tissues suffering from water loss. Biochem. Biophys. Res. Commun. 352:831-835.

Maskin, L., S. Maldonado, and N.D. Iusem. 2008. Tomato leaf spatial expression of stress-induced Asr genes. Mol. Biol. Rpt. 35:501-505.
Miao, Y., D. Lv, P. Wang, X.C. Wang, J. Chen, C. Miao, and C.P. Song. 2006. An Arabidopsis glutathione peroxidase functions as both a redox transducer and a scavenger in abscisic acid and drought stress responses. Plant Cell 18:2749-2766.

Millar, A.H., J.L. Heazlewood, B.K. Kristensen, H.P. Braun, and I.M. Møller. 2005. The plant mitochondrial proteome might contain as many as 2000-3000 different gene products. Trends Plant Sci. $10: 36-43$.

Mirzaei, M., N. Soltani, E. Sarhadi, D. Pascovici, T. Keighley, G.H. Salekdeh, P.A. Haynes, and B.J. Atwell. 2012. Shotgun proteomic analysis of long-distance drought signaling in rice roots. J. Proteome Res. 11:348-358.

Mou, Z.L., Y. He, Y. Dai, X. Liu, and J. Li. 2000. Deficiency in fatty acid synthase leads to premature cell death and dramatic alterations in plant morphology. Plant Cell 12:405-417.

Muñoz, A. and M.M. Castellano. 2012. Regulation of translation initiation under abiotic stress. Comp. Funct. Genomics. doi: 10.1155/ 2012/406357.

Olvera-Carrillo, Y., F. Campos, J.L. Reyes, A. Garciarrubio, and A.A. Covarrubias. 2010. Functional analysis of the group 4 late embryogenesis abundant proteins reveals their relevance in the adaptive response during water deficit in Arabidopsis. Plant Physiol. 154:373390.

Owttrim, G.W. 2006. RNA helicases and abiotic stress. Nucleic Acids Res. 34:3220-3230.

Plafker, S.M. and I.G. Macara. 2002. Ribosomal protein L12 uses a distinct nuclear import pathway mediated by importin 11. Mol. Cell. Biol. 22:1266-1275.

Pockley, A. 2005. Molecular chaperones and cell signaling. Cambridge University Press, Cambridge, UK.

Price, A.H., J.E. Cairns, P. Horton, H.G. Jones, and H. Griffiths. 2002. Linking drought-resistance mechanisms to drought avoidance in upland rice using a QTL approach: Progress and new opportunities to integrate stomatal and mesophyll responses. J. Expt. Bot. 53:9891004.

Rick, C.M. 1973. Potential genetic resources in tomato species: Clues from observation in native habitats, p. 255-269. In: Srb, A.M. (ed.). Genes, enzymes and populations. Plenum Press, New York, NY.

Rodríguez-Gamir, J., G. Ancillo, F. Aparicio, M. Bordas, E. PrimoMillo, and M.Á. Forner-Giner. 2011. Water-deficit tolerance in citrus is mediated by the down regulation of PIP gene expression in the roots. Plant Soil 347:91-104.

Scheper, G.C., M.S. van der Knaap, and C.G. Proud. 2007. Translation matters: Protein synthesis defects in inherited disease. Nat. Rev. Genet. 8:711-723.

Schönbrunner, E.R. and F.X. Schmid. 1992. Peptidyl-prolyl cis-trans isomerase improves the efficiency of protein disulfide isomerase as a catalyst of protein folding. Proc. Natl. Acad. Sci. USA 89:4510-4513.

Schoonheim, P.J., M.P. Sinnige, J.A. Casaretto, H. Veiga, T.D. Bunney, R.S. Quatrano, and A.H. de Boer. 2007. 14-3-3 adaptor proteins are intermediates in ABA signal transduction during barley seed germination. Plant J. 49:289-301.

Schroeder, J.I., J.M. Kwak, and G.J. Allen. 2001. Guard cell abscisic acid signaling and engineering drought hardiness in plants. Nature 410:327-330.

Schuppler, U., P.H. He, P.C.L. John, and R. Munns. 1998. Effect of water stress on cell division and cell-division cycle 2-like cell-cycle kinase activity in wheat leaves. Plant Physiol. 117:667-678.

Shinozaki, K. and K. Yamaguchi-Shinozaki. 2007. Gene networks involved in drought stress response and tolerance. J. Expt. Bot. 58:221-227.

Simitsopoulou, M., H. Avila, and F. Franceschi. 1999. Ribosomal gene disruption in the extreme thermophile Thermus thermophilus HB8. Generation of a mutant lacking ribosomal protein S17. Eur. J. Biochem. 266:524-532.

Thipyapong, P., J. Melkonian, W.D. Wolfe, and J.C. Steffens. 2004. Suppression of polyphenol oxidases increase stress tolerance in tomato. Plant Sci. 167:693-703. 
Tommasini, L., J.T. Svensson, E.M. Rodriguez, A. Wahid, M. Malatrasi, K. Kato, S. Wanamaker, J. Resnik, and T.J. Close. 2008. Dehydrin gene expression provides an indicator of low temperature and drought stress: Transcriptome-based analysis of barley (Hordeum vulgare L.). Funct. Integr. Genomics 8:387-405.

Tuteja, N. and S.K. Sopory. 2008. Chemical signaling under abiotic stress environment in plants. Plant Signal. Behav. 3:525-536.

Vainberg, I.E., S.A. Lewis, H. Rommelaere, C. Ampe, J. Vandekerckhove, H.L. Klein, and N.J. Cowan. 1998. Prefoldin, a chaperone that delivers unfolded proteins to cytosolic chaperonin. Cell 29:863-873.

Vandeleur, R.K., G. Mayo, M.C. Shelden, M. Gilliham, B.N. Kaiser, and S.D. Tyerman. 2009. The role of plasma membrane intrinsic protein aquaporins in water transport through roots: Diurnal and drought stress responses reveal different strategies between isohydric and anisohydric cultivars of grapevine. Plant Physiol. 149:445-460.

Vassileva, V., L. Simova-Stoilova, K. Demirevska, and U. Feller. 2009. Variety-specific response of wheat (Triticum aestivum L.) leaf mitochondria to drought stress. J. Plant Res. 122:445-454.

Vierstra, R.D. 1993. Protein degradation in plants. Annu. Rev. Plant Physiol. Plant Mol. Biol. 44:385-410.

Wang, Y., F. Yang, M.A. Gritsenko, Y. Wang, T. Clauss, T. Liu, Y. Shen, M.E. Monroe, D. Lopez-Ferrer, T. Reno, R.J. Moore, R.L. Klemke, D.G. Camp, II, and R.D. Smith. 2011. Reversed-phase chromatography with multiple fraction concatenation strategy for proteome profiling of human MCF10A cells. Proteomics 11:2019-2026.

Wessel, D. and U.I. Fugge. 1984. A method for the quantitative recovery of protein in dilute solution in the presence of detergents and lipids. Anal. Biochem. 138:141-143.

Wilkinson, B. and H.F. Gilbert. 2004. Protein disulfide isomerase. Biochim. Biophys. Acta 1699:35-44.

Xia, H., L. Camus-Kulandaivelu, W. Stephan, A. Tellier, and Z. Zhang. 2010. Nucleotide diversity patterns of local adaptation at drought-related candidate genes in wild tomatoes. Mol. Ecol. 19:4144-4154.

Xiao, S. and M.L. Chye. 2011. New roles for acyl-CoA-binding proteins (ACBPs) in plant development, stress responses and lipid metabolism. Prog. Lipid Res. 50:141-151.

Xiong, L., K.S. Schumaker, and J.K. Zhu. 2002. Cell signaling during cold, drought, and salt stress. Plant Cell 14:S165-S183.

Xu, G.Y., P.S. Rocha, M.L. Wang, M.L. Xu, Y.C. Cui, L.Y. Li, Y.X. Zhu, and X. Xia. 2011. A novel rice calmodulin-like gene, OsMSR2, enhances drought and salt tolerance and increases ABA sensitivity in Arabidopsis. Planta 234:47-59.

Xu, Z.F., W.Q. Qi, X.Z. Ouyang, E. Yeung, and M.L. Chye. 2001. A proteinase inhibitor II of Solanum americanum is expressed in phloem. Plant Mol. Biol. 47:727-738.

Yamasaki, S. and P. Anderson. 2008. Reprogramming mRNA translation during stress. Curr. Opin. Cell Biol. 20:222-226.

Yan, J., C. He, J. Wang, Z. Mao, S.A. Holaday, R.D. Allen, and H. Zhang. 2004. Overexpression of the Arabidopsis 14-3-3 protein GF14 $\lambda$ in cotton leads to a 'stay-green' phenotype and improves stress tolerance under moderate drought conditions. Plant Cell Physiol. 45:1007-1014.

Yang, Y., X. Qiang, K. Owsiany, S. Zhang, T.W. Thannhause, and L. Li. 2011. Evaluation of different multidimensional LC-MS/MS pipelines for iTRAQ-based proteomic analysis of potato tubers in response to cold storage. J. Proteome Res. 10:4647-4660.

Zhang, H., S. Dong, M. Wang, W. Wang, W. Song, X. Dou, X. Zheng, and Z. Zhang. 2010. The role of vacuolar processing enzyme (VPE) from Nicotiana benthamiana in the elicitor-triggered hypersensitive response and stomatal closure. J. Expt. Bot. 61:3799-3812.

Zhang, J., T. Liu, J. Fu, Y. Zhu, J. Jia, J. Zheng, Y. Zhao, Y. Zhang, and G. Wang. 2007. Construction and application of EST library from Setaria italica in response to dehydration stress. Genomics 90:121-131.

Zhang, S.W., C.H. Li, J. Cao, Y.C. Zhang, S.Q. Zhang, Y.F. Xia, D.Y. Sun, and Y. Sunday. 2009. Altered architecture and enhanced drought tolerance in rice via the down-regulation of indole-3-acetic acid by TLD1/OsGH3.13 activation. Plant Physiol. 151:1889-1901.

Zhang, Z., S. Zhang, Y. Zhang, X. Wang, D. Li, Q. Li, M. Yue, Q. Li, Y. Zhang, Y. Xu, Y. Xue, K. Chong, and S. Bao. 2011. Arabidopsis floral initiator SKB1 confers high salt tolerance by regulating transcription and pre-mRNA splicing through altering histone H4R3 and small nuclear ribonucleoprotein LSM4 methylation. Plant Cell 23:396-411.

Zhou, S.P., R.J. Sauvé, T. Fish, and T.W. Thannhauser. 2009. Salt induced and salt repressed protein in tomato. J. Amer. Soc. Hort. Sci. 134:289-294.

Zhou, S.P., R.J. Sauvé, Z. Liu, S. Reddy, S. Bhatti, S.D. Hucko, T. Fish, and T.W. Thannhauser. 2011. Identification of salt-induced changes in leaf and root proteomes of the wild tomato, Solanum chilense. J. Amer. Soc. Hort. Sci. 136:288-302. 